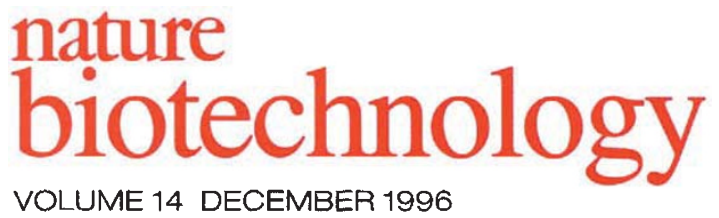

\title{
Soya, supermarkets, sense and segregation
}

The Monsanto Corporation (St. Louis, MO) has really opened a "can of beans" in Europe. Instead of listening to the groups that would be responsible for marketing their "Roundup Ready" soybean-a recombinant plant that can be grown more aggressively through the use of Monsanto's herbicide Roundup-the company ignored everyone's input except their own "bean counters" and shipped tons of these beans to soy processors in Europe. How resistant are Europeans to being "rounded up" by a multinational corporation and fed a biotechnology product they are unsure of? Protesters have chained themselves to soy processors' gates in Germany, climbed onto Nestlés roof in Vevey, Switzerland, occupied the office of the Austrian Health Minister, and taken off their clothes in Rome at the World Food Summit. Biotechnology is accustomed to "Green" opposition to its new products. But Monsanto's latest move seems to have alienated everyone. Even the retail and wholesale organizations the company had counted as allies have turned against this product: Hans Kroner, secretary-general of Eurocommerce, representing retailers in 20 European countries, recently called for Roundup Ready to be segregated from "regular" beans.

What's dismaying is not that Kroner was speaking out of turn, but that he was forced to speak in the wrong company. Earlier this year, European retail and wholesale groups had asked Monsanto to establish, with the various growers and processors in the United States, separate streams for the Roundup Ready. They did this for a variety of reasons: Retailers in France, Denmark, the Netherlands, and the United Kingdom wanted segregation so that they could label the products appropriately. German, Austrian, Finnish, and Swedish retailers wanted a separate stream so that they could exclude genetically manipulated food either "for the foreseeable future" or "until consumers are happy." Their Norwegian and Swiss counterparts simply can't take the product until it has been approved for import.

But Monsanto remained unresponsive, arguing, quite rightly, that thousands of different processed food products have soybeans as an ingredient, and that the products are distinguishable only in insignificant details. The regulators and, indeed, most of the retailers agree.

Where Kroner went wrong was in sharing a platform with his host, Jeremy Rifkin of the Foundation on Economic Trends (FET, Washington, DC), and with Hiltrud Breyer, a German Green member of the European Parliament (Strasbourg, France) and a longtime opponent of genetic engineering. Both wielded aging, but still effective, broadswords, swiping at biotechnology with strokes learned at the "playing God" school of fencing. Kroner was more subtle, of course. But he was unwise, of course, or naive at the least, if he thought that the green antibiotechnology zealotry would not reflect on him. Rifkin and Breyer called for a total boycott. Kroner was coopted by default. And Kroner should know how that game is played. To an extent, Monsanto has repeated the same blind assumption about the European market that marooned its bovine somatotropin product: That Europe is, in essence, identical to North America.

Monsanto's biggest mistake was assuming consumers are wholly rational. They are clearly not. How else could you explain bottled water, potato chips tasting of roast beef, decaffeinated coffee, or sugarfree, fat-free, diet ice-cream. What matters to retailers and to whole- salers, is the perception of products.

Monsanto has fought, irrationally, for the intellectual high ground. With science on its side, Monsanto argued that segregation would be technological apartheid. With economics on its side, Monsanto argued that it would invoke extra costs. With the law on its side, Monsanto correctly argued that it has done everything regulators required.

Monsanto has the allies of reason. But market sentiment is not one of them. It should have kept the European retailers on its side.

\section{FDA needs to regulate genetic "home brews"}

The US Food and Drug Administration (FDA, Rockville, MD) needs to muster the political will to take up the regulation of genetic testing, not just of diagnostics manufactured as kits, but also of the in-house protocols ("home brews") that constitute most genetic susceptibility tests (see p. 1642). Although the US Health-Care Financing Administration does have some oversight (under the Clinical Laboratory Improvement Amendment of 1988), as do institutional review boards at various institutions, the oversight provided varies widely and does not inspire confidence in the end results.

Currently, FDA is fending off the issue, saying it hasn't got the time or resources to deal with genetic testing-they are only tests after all, and not potentially toxic drugs. But it must come to grips with these tests now, even if they aren't an easy target like tobacco and won't win FDA any popularity contests. Genetic testing issues are scientific, economic, and deeply political: Biotechnology and pharmaceutical companies, health-care management organizations and health insurers, consumer advocacy groups, patients and physicians find themselves arrayed in strange alliances on both sides of the pro- and antiregulation issue.

In a utopian world, the companies that are marketing these tests would work together to self-regulate and to prevent products that are premature from reaching the market. In a real world that is fiercely competitive, and in which genetic tests are the only tangible products these companies will have for the next decade or so, FDA oversight is necessary, not in perpetuity, but for the next 10-15 years. During this period, by most accounts, the ability to make and sell genetic tests will far outstrip medicine's ability to accurately interpret their results or to offer effective prophylactic or therapeutic remedies.

Test guidelines recommended by the American Society of Human Genetics and those drafted by the US Task Force on Genetic Testing are admirable, and FDA should turn to them for guidance. While these guidelines are necessary, they are not sufficient: Many responsible companies will follow them, but other, get-rich-quick operations will simply ignore them. FDA regulations that intersect the flow of commercial activity have teeth that guidelines can only aspire to. And in the end, sensible oversight cannot but help biotechnology. At the moment, a company offering inappropriate tests is not breaking anyone's rules. And if safeguards are not put in place soon, one such rogue company could undermine the fledgling testing enterprise for the entire sector. 